\title{
$O$ romance de Osman Lins: experimentalismo e tradição
}

Maria do Carmo Lanna Figueiredo UFMG/PUC Minas

Resumo: Visão geral da obra do escritor Osman Lins (1924-1978), com o objetivo de esclarecer alguns procedimentos de que o autor se utiliza ao inovar a tradição.

Palavras-chave: Osman Lins, Romance contemporâneo, Tradição e experimentação.

$\mathrm{O}_{\text {sman Lins bem exemplifica o perfil do profissional de letras }}$ brasileiro do século XX. Professor de literatura da Universidade Estadual de São Paulo em Marília; articulista de jornais e revistas; ensaísta de periódicos especializados e de prefácios; tradutor; teatrólogo; contista; escritor de "casos especiais" para a TV; romancista. No conjunto de sua produção, podem-se sublinhar manifestações que evidenciam tanto a ampla consciência de sua importância - seu lastro individualizado, experimentalismo -, quanto a face exterior que repercute nele - as experiências de outros que o deslocam e antagonizam, tradição. O título deste artigo, O romance de Osman Lins: experimentalismo e tradição, refere-se à presente perspectiva de abordagem da obra, com o objetivo de esclarecer alguns mecanismos de que o autor se utiliza ao inovar a tradição. 
Pode-se avaliar a posição da obra de Osman Lins na Literatura Brasileira pelos depoimentos da crítica e do autor, e, principalmente, por sua ficção. O escritor procura atender à necessidade de aliar qualidade à comunicação, mediante a tentativa de estabelecer um elo entre as vertentes mais específicas da arte literária nacional: por um lado, aquela que expressa o desejo das transformações sociais e que opta por veicular um sentido que the é preexistente, ligada às tendências "realista, naturalista, regionalista", de maior aceitação junto ao leitor; e, por outro, a literatura de experimentação, cujo enfoque abona o aspecto metalinguístico e, portanto, recusa-se às definições, às afirmações generalizantes e às convicções dogmáticas, sendo esta a índole mais marcante do escritor.

O esforço nesse sentido repercute na fortuna crítica da obra, que parece responder à peculiaridade de sua inserção na Literatura Brasileira. Pode-se considerá-lo um autor bem posicionado dentro das perspectivas de mercado literário no Brasil, uma vez que conseguiu viver de sua produção. Sua obra atingiu o público não especializado e o sistema educacional, que o incluiu entre os autores objeto de teses universitárias. Muitos livros seus foram traduzidos no exterior. Situa-se entre aqueles escritores que, não alcançando um destaque excepcional de editoração e reconhecimento absoluto da elite cultural do país, conseguiram manter, no entanto, uma média de aceitação invejável, se se levar em conta o pequeno espaço que a sociedade brasileira destina ao literário.

Atente-se, para exemplificar a questão, à opinião de Davi Arrigucci Jr. e de Antonio Candido, que comentam o bom nível da produção literária do autor e a aceitação de seus livros junto aos leitores. Os ensaístas situam-no entre os escritores brasileiros que dão continuidade à busca de domínio técnico e a experimentações, desenvolvidos a partir do realismo. Para os críticos, isso representa a consolidação de uma linha de produção que garante à Literatura Brasileira uma continuidade sistemática e que lhe assegura um nível literário elevado. ${ }^{1}$ Trata-se, pois, de uma obra que se inclui entre aquelas que garantem o lugar da literatura elaborada na sociedade brasileira.

A obra de Osman Lins admite o entrecruzamento de vários tipos de linguagem, em vista do material diverso e fluido de que se utiliza. Uma literatura de resistência, porque questiona a exiguidade do espaço literário no universo

1. Cf. ARRIGUCCI. Achados e perdidos, p. 113 e CANDIDO. A educação pela noite, p. 205. 
sociocultural do Brasil. Tal questionamento poderá ser mais bem apreendido, acompanhando-se entrevistas e ensaios do autor. Osman Lins não se furtou a pronunciar-se sobre o papel do escritor e a função da literatura, tendo deixado uma contribuição rica e consciente em obras, algumas compiladas e editadas pela escritora Julieta de Godoy Ladeira, a quem muito se deve este precioso trabalho. ${ }^{2}$

A análise de sua ficção também possibilita acompanhar a resistência do escritor aos percalços que envolvem a literatura na contemporaneidade, porque esta se posiciona face aos vários agentes delimitadores das instâncias envolvidas na comunicação literária. Tal atributo incita a solidariedade ativa entre realidade ficcional e realidade circundante e deixa filtrar diferentes vozes e linguagens que acabam por multiplicar, em deslizamento, o sujeito da produção artística e a instância autoral.

Dessa forma, reflete a impossibilidade da percepção de uma mensagem única e definitivamente estabelecida, ao mesmo tempo em que põe em pauta o universo literário em diálogo com a sociedade. Ou seja, deixa entrever: o intercâmbio entre as instâncias envolvidas na comunicação literária; a convergência dos vários influxos que a informam; a interação do livro com o contexto no qual se insere; a importância da memória coletiva e individual na obra; as diretrizes impostas pelo mercado que regem o consumo e que manipulam o gosto estético; os mecanismos textuais de que o escritor se vale para conviver com tal situação.

Marcadamente a partir de Nove, novena (1966), a força ficcional do autor recai na deliberada escolha de um tipo de narrativa apoiada no presente contínuo, sempre ansiando por uma expressividade que "fuja às convenções já mortas e às convenções em fase de agonia." Evitando "a repetição de fórmulas experimentadas e aprovadas", porque, para ele, "o que foi feito, está morto", reconhece, porém, que suas inovações partem das conquistas de outros, no território sem fronteiras da literatura. Ressalta, ainda, sua diferença em relação aos escritores vanguardistas, que assumem a transgressão como fundamental, preferindo realçar sua condição de "beneficiário da literatura, de toda literatura."

As novelas do volume distanciam-se das tradicionais pela perspectiva e foco narrativo. Nelas se introduz a mediação dos sinais gráficos que auxiliam a compreensão dos diálogos por parte do leitor, e, ao mesmo tempo, aproximam a

2. LINS. Evangelho na taba, por exemplo.

3. LINS. Jornal do Comércio, apud LINS. Evangelho na taba, p. 51. 
narrativa da música e das artes plásticas. Ambos os aspectos serão retrabalhados posteriormente em Avalovara e Missa do galo, variações sobre o mesmo tema.

Conta-se que Osman Lins acompanhava de perto e opinava sobre a capa de seus livros. A figura 1 mostra o cuidado formal esboçado na capa de Kélio Rodrigues de Oliveira.

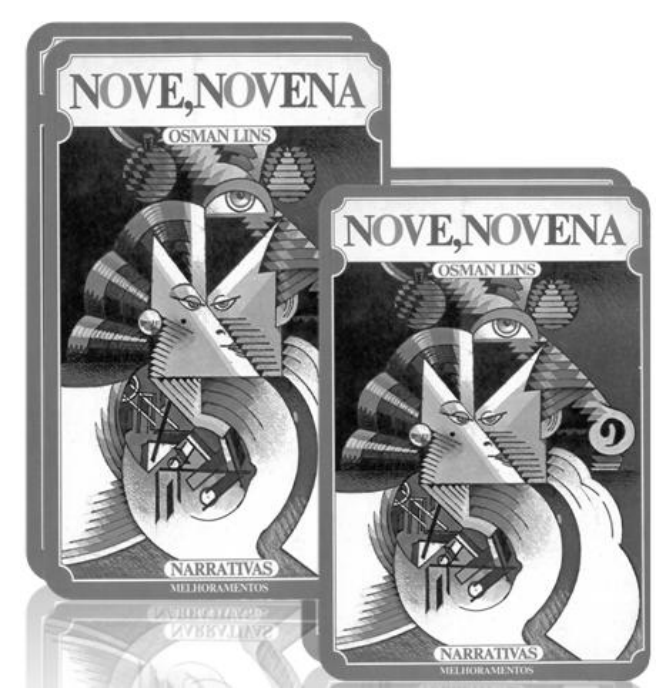

Figura 1. São Paulo: Melhoramentos, 1966 e 1975. As edições mantiveram a mesma capa, de Kélio Rodrigues de Oliveira.

O exemplo da figura 2 foi retirado da $5^{\underline{a}}$ novela do volume, "Retábulo de Santa Joana Carolina", narrativa que se compõe de diversos relatos justapostos sobre episódios da vida da heroína, os mistérios. Pela justaposição, encontram-se, no espaço literário presente, a realidade nordestina brasileira e a realidade medieval do retábulo religioso. 


\section{SETTIMO MISTERIO}

Os que fien o tesem unem o codenas materiais dispersos que, de outro medo, seriam viss os guase. Pertencena à mesma linhagem FLANDEIRA CARNEIRO FUSO LX dos gotootras, estabelecer lets - poctos de untio para o desino. Astes do fuso, da roca, do tear, das invengiós destinalas a estender LX LINHO CASULO ALCODSO LX

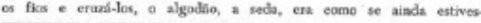
TECEDETA URDIDURA TEAR LX sem tressos no lambo, nas trovas

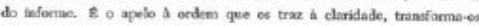
em obass, pertanto en objetes hunasos, flusinados pelo espirito des hamem. Nấ é por ser-nos úteés LX THAMA CEOCHE DESENHO LA

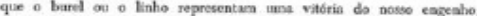

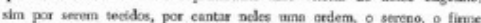

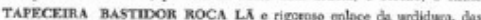

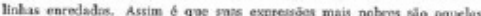

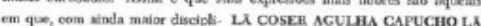

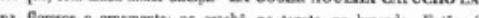

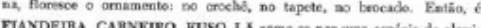

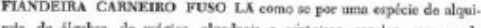

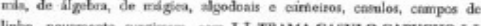
linho, nowianente stagissem, cona LX TRAMA CASULO CAPUCHO LX itbelde, portm maks perdarive.

$\longrightarrow$ Não tínhamos sequer regador. Minha mãe, curvada, nos dá um clister de pimenta dágua, com bexiga de boi e canudo de carrapateira, untado com banha de porco. A doença era febre, o corpo cheio de manchas. Comiamos pouco, sempre estávamos propensos a calr de cama. Antes, foi a tosse convulsa. Tossiamos todos, o couro de Álvaro estourou abalxo do ouvido. Foi quem mais sofreu. Tomou duas almotolias de óleo de fígado, duas colheres por dia, meia laranja após a colherada. Gostava de laranjas, queria chupar uma inteira, mamãe não defxava: saía muito caro. Tudo era pela metade. Meia.

\section{NONO MISTERIO}

P A L A V Dus vezes fol crado o munda: gequndo pasion do R A C A P nada para o existecte; e queardo, alçado a um plano mais

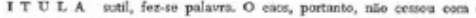
E P A L I aparedimento do triversos mas quando a conscitocia do M P S E S heemen, nomeando o crioda, recriandoo potiato, sepanos,

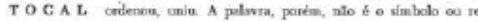
I G B A F flew do que significa, fursho servil, e sim o see espirito, I A H 1 E o suppe ns argila. Uma coisa nio exise realmente en.

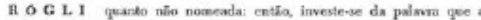
F O P L U Alumina $e$, kggrando ideatidack, adjulre igualmente eta ti-

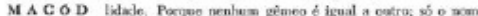

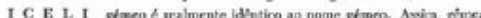

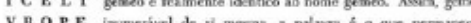

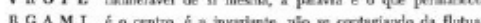
хно

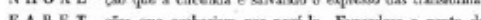

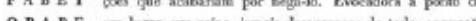

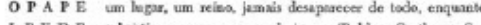
L P E D R sulustir o nowe que os designos (Bybles, Cartiaga, Sa

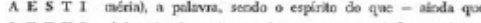
L E T E I so imigimarianonte - criste, petminece aied, por fincor L U M I N ruptivel, eamo o esplendor do que fol, podendo, mesere U K A E 5 tranemigrads, messo esquecidh, ser restegrede cen sea

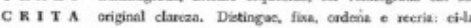

D) Nós dois de braços dados, as caras entransadas, parecemos olhar, ao mesmo tempo, um par outro e os dois para a frente. As nossas costas, de flanco, os pescoços cruzados, uma cauda para esquerda e outra para a direita, brancas, largas, arrastando no chão feito vestidos de noiva, nossos dois cavalos. Brilhando sobre nós, duas estrelas, crandes e rubras 1 Uma sobre a cabeca de Miguel: parece uma rosa. Outra sobre a cabeça 106

Figura 2. Textos retirados da novela "Retábulo de Santa Joana Carolina", composta por 12 mistérios, onde se notam renovações, tanto no uso de símbolos gráficos (p. 106) como na organização do material narrativo (p. 117).

No que diz respeito a Avalovara, cumpre lembrar o sucesso de vendagem que o romance obteve, tendo ficado entre as dez ficções mais vendidas no levantamento da revista Veja, em 1973. Nele aprofunda-se a experimentação gráfica, iniciada no livro anterior. A capa, como a de Nove, novena, é de autoria de Kélio Rodrigues de Oliveira.

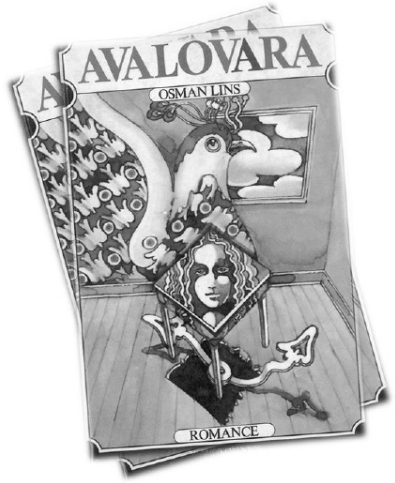

Figura 3. São Paulo: Melhoramentos, 1973. Id. Ibid. 1974 (2. e 3. ed.). Capa de Kélio Rodrigues de Oliveira. A 4a. edição, da Guanabara (1986), modifica a capa, mas obedece à mesma disposição de texto nas páginas, o que não será considerado pela 5ª . edição (1995), da Companhia das Letras. 
Seguindo elaborada geometria, espécie de guia metalinguístico do leitor, Avalovara conta a história de Abel e de seu envolvimento com três mulheres, na Europa, em Recife e em São Paulo.

O quadrado, que aprisiona o palíndromo latino "SATOR AREPO TENET OPERA ROTAS", é invadido pela espiral que vai tocando, sucessivamente, as letras. Cada uma corresponde a um tema da narrativa, que volta em segmentos sempre maiores. Pode-se ler seguidamente o enredo, os oito temas intercalados uns aos outros, ou de acordo com o Índice dos Temas, aposto ao final do volume.
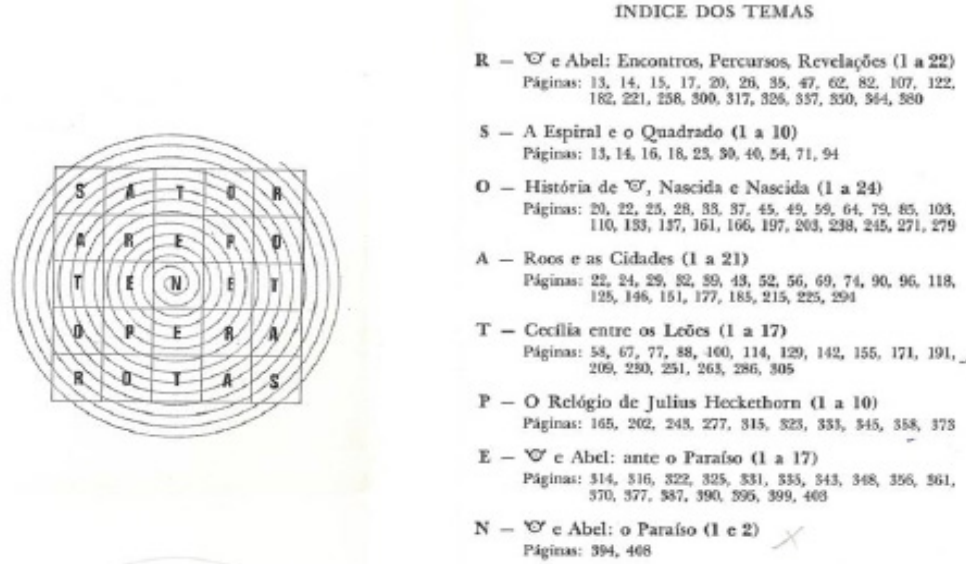

Figura 4. O palíndromo onde se insere a espiral, indiciando a relação entre Criador e Criatura no romance (p. 8) e o Índice de Temas (p. 415), dados em que se concretiza o caráter geométrico do livro.

Pelo exposto, pode-se situar a ficção de Osman Lins numa vertente da Literatura Brasileira que, embora absorva o desvendamento da realidade social na ficção, se desenvolve como marca de diferença na tradição do romance brasileiro, assumida e levada adiante pelo modernismo dos anos 30.

Ao encarar a literatura como um compromisso com a palavra, com a língua materna e com o povo a que está ligada, Lins assume uma postura combativa em relação a tudo que possa impedir a realização desse compromisso. Tal postura acha-se, de algum modo, explicitada em títulos de livros seus, como: Guerra do cansa-cavalo (1967), Guerra sem testemunhas, o escritor, sua condição e a realidade social (1969), A rainha dos cárceres da Grécia (1976), Do ideal e da glória, problemas inculturais brasileiros (1977), Evangelho na taba, outros problemas inculturais brasileiros (1979). 
A meu ver, Osman Lins manifesta uma concepção da literatura como o resultado de várias percepções individualizadas e incompletas, fator que permite realçar a diversidade de sua significação e a possibilidade de sua permanência no tempo. Além disso, os depoimentos evidenciam algumas coordenadas do pensamento de Osman Lins sobre a leitura. E apoiam a hipótese de que uma das soluções oferecidas pelo escritor para assegurar-se uma posição na sociedade que o marginaliza passa pela inclusão do leitor no processo de criação e circulação do livro.

O fato parece ser comum à época e pode ser constatado pela resposta dos escritores à situação de marginalidade involuntária em que se encontram, considerada em triplo aspecto: as desigualdades sociais, que dificultam o denominador comum de reciprocidade entre o intelectual e o povo; o momento político ditatorial, que agride a liberdade do indivíduo e da sociedade; e o mercantilismo da sociedade de consumo, que solapa o lugar do livro na circulação das ideias. A década é fértil em um tipo de produção literária autorreflexiva, voltada para a sua especificidade, elegendo-se como assunto de si mesma, enquanto se assume como fator de resistência política, expressão da dialética entre espaço literário e espaço social. ${ }^{4}$

Gostaria de destacar um aspecto da questão, na atualidade, que pode ser considerado como subjacente a esse eixo: o desejo do escritor de comunicar-se de forma literária e pessoal com um público pressionado pelo dirigismo editorial, na prática de seleção de leitura. Antes, o problema basicamente consistia em formar um público para a obra literária, numa sociedade em que o divórcio entre elite cultivada e povo parecia intransponível. A situação era agravada pela inexistência de um mercado editorial e por toda uma tradição cultural que sonegava ao livro - e a seus escritores - um campo de ação específico e atuante. Várias tentativas de solucionar esses constantes entraves à divulgação das obras vão ser oferecidas pelos interessados. ${ }^{5}$ Ressalte-se a importância cada vez maior do papel do leitor, no momento em que, já existindo a editoração brasileira, ela se concretiza principalmente regida pelo mercado.

Osman Lins evidencia essa percepção, com outros escritores contemporâneos seus. Transformando o material lido e assimilado, o autor tenta

4. Cf. SAntiago. Vale quanto pesa, p. 127-33.

5. Cf. Costa lima. Dispersa demanda, p. 3-29. 
dar continuidade a um ofício que se declara dependente da contribuição de muitos, inclusive do leitor, por considerar que a obra literária é também tudo o que se escreve sobre ela.

Nesse aspecto, pode-se considerar a leitura criativa de Machado de Assis, desenvolvida na coletânea Missa do Galo, variações sobre o mesmo tema (1976), como outra possibilidade de inovar a tradição na obra osmaniana. Revelando-se explicitamente como seguidores-leitores de Machado de Assis, os escritores participantes do livro inserem por seus contos a contribuição pessoal desejada e desejável à obra do mestre.

Capa, ficha de catalogação e índice tornam-se indicações de leitura a influenciar sua correta interpretação.
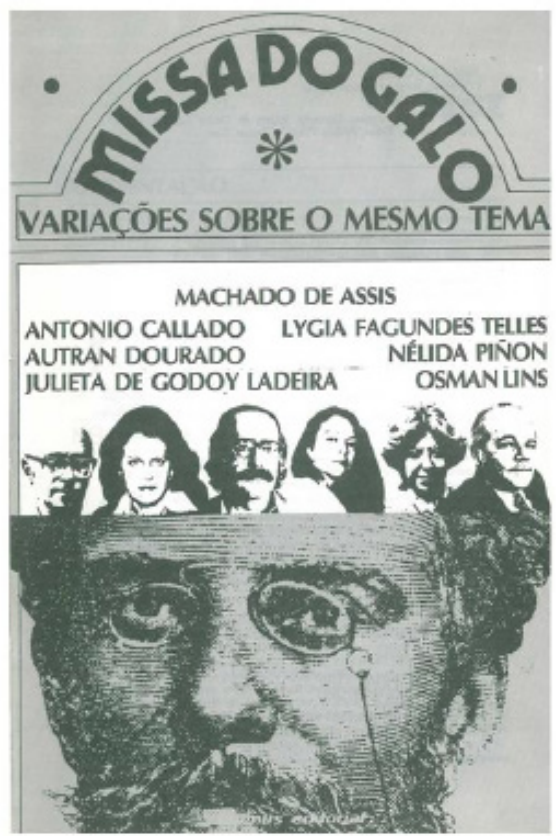

Figura 5. Missa do Galo, variações sobre o mesmo tema. São Paulo: Summus, 1977. A capa deixa entrever a filiação, também expressa no título e no detalhe que a ficha de catalogação complementa: os autores em ordem alfabética, posteriormente ao nome de Machado de Assis, seguidos pelas datas de seu nascimento e morte.

6. LINS. Veja, apud LINS. Evangelho na taba, p. 241. 


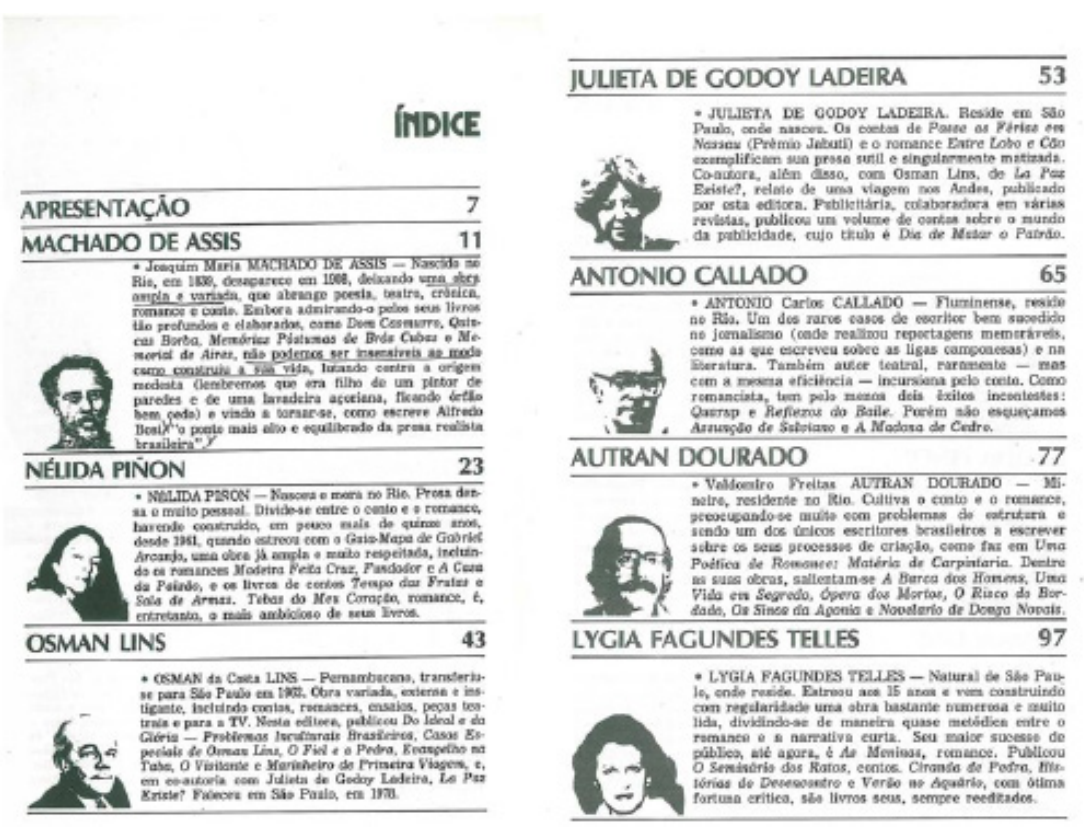

Figura 6. O índice do volume traz indicação de leituras na apresentação dos autores, na ordem dos contos, nas gravuras que os precedem.

Acredito que a produção osmaniana deixe entrever ainda, no ângulo da recepção, a eleição da leitura como fundadora da história do passado. Afirmando-se como leitor provisório, admite a historicidade da literatura e o risco de se contrapor ao já estabelecido como certo e definitivo, como se pode observar em Missa do galo, variações sobre o mesmo tema e no ensaio Lima Barreto e o espaço romanesco. A mesma perspectiva perpassa A rainha dos cárceres da Grécia, quando problematiza o lugar do sujeito no processo criador.

Jean-Charles Gateaux comenta o aspecto mencionado, acentuando a recusa ao naturalismo e ao formalismo de $A$ rainha dos cárceres da Grécia, como uma síntese original e realizada das promessas de Avalovara (1973). ${ }^{7}$ O fato é também reconhecido pelo comentário do Le Monde, por ocasião do lançamento do livro pela Gallimard, em tradução de Maryvonne Lapouge. A nota do jornal evidencia a relação do romance com outros escritores contemporâneos, ao

7. GATEAUX. Trois romans parlent de leur pays et du monde par des voix des femmes. 
mesmo tempo em que reconhece nele um quadro da cultura brasileira, traçado sob um ângulo não somente sociológico. Termina por afirmar que: "[...] L'ouvre d'Osman Lins constitue, en quelque sorte, le contrepoint à la grande école réaliste brésiliènne dont le réprésentant le plus connu en France est incontestablement Jorge Amado."

Interessante considerar aqui a leitura que Osman Lins faz do escritor baiano em sua obra. Para o autor, a Gorda, personagem de Avalovara, "é uma personagem construída à minha maneira, copiando as personagens de Jorge Amado", "a cópia de um personagem de Jorge Amado visto por Osman Lins." Nas características da personagem osmaniana à Jorge Amado, gostaria de realçar a leitura de acatamento de recursos narrativos diferentes dos seus, em sua preocupação de estabelecer um diálogo entre literatura e sociedade; o apelo ao leitor; e uma leitura irônica do valor de mercadoria das personagens do escritor baiano.

A diferença que a crítica estrangeira aponta em $A$ rainha dos cárceres da Grécia com relação ao romance brasileiro de maior veiculação no exterior, por suas características de cor local e pitoresco, pode ser considerada uma constante na obra do escritor. O nordeste já aparece sob esta feição desde O fiel e a pedra (1961), assim como em "O retábulo de Joana Carolina" de Nove, novena e no episódio "T-Cecília entre os leões" de Avalovara. A rainha dos cárceres da Grécia aprofunda esse veio de sua ficção, quando apresenta o Recife invadindo São Paulo, a escritora nordestina Julia participando das ligas camponesas e a doméstica Maria de França simbolicamente retratando o drama do retirante urbanizado.

O romance compõe-se com trechos de jornais da década de 70 , combinações de textos literários e históricos de várias épocas, retalhos de lembranças das personagens. Esses fragmentos acolhem a tensão entre lembrar e esquecer, verdade e invenção, aventada pela gata Memosina que, esquecendo-se da própria natureza, se confunde com rato, galinha, lontra. Metonímia da ficção de que participa, o animal concretiza o jogo do esquecimento e da lembrança que, refletido nela, permite o ir e vir do romance aos gêneros ensaio e diário, assim como permite à obra ligar-se à realidade histórica e ficcional, ao presente e ao passado.

8. Le Monde. Un tableaux de la culture brèsilienne.

9. LINS. Evangelho na taba, p. 223. 
Note-se que na figura 7, da capa da edição Melhoramentos, também de Kélio Rodrigues, frente e verso apresentam a mesma figura. A figura 8 mostra páginas do romance onde se destacam: citações, notas ao pé de página, diferença marcante quanto ao número de linhas por página.
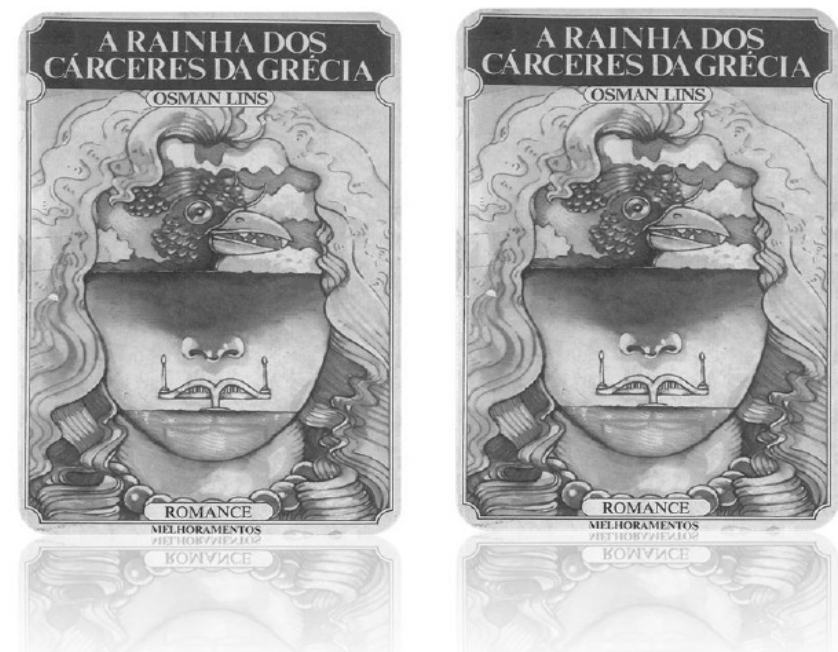

Figura 7. São Paulo: Melhoramentos, 1976. Frente e verso da capa, também de Kélio Rodrigues de Oliveira

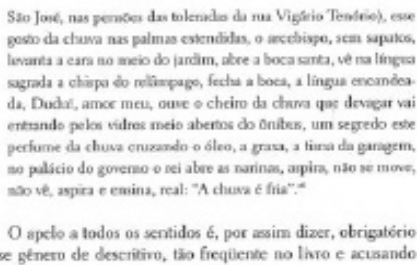
iesse generu de descrition, tis fieqiente no likro e acisando tais variaşōes que justificaria estudo à parte.

\section{4 de desembro}

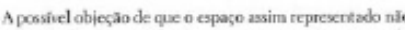
expressa oabciència, nads mais sendo que o refless do modo como atas a imaginasto da personagem, puecce nefotada ei outros pentos do testo, a năo ser que se toene por fala boda. namativa de Maria de França:

Vena a chuxa do mar, atinge o cais do porto, aramca pasa cina dia

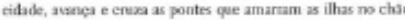

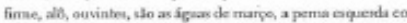

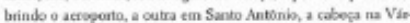

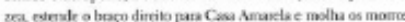
a

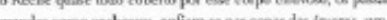

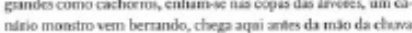

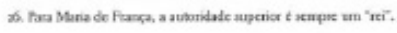

8. que relox desee mo morso e me aleanç ainda mo çuintal e at ceeno pers dentro, babem an poetan, um porebo pouse ne veto es case grane, owem?"

A percepcito neal da chava (a cheva no quintal onde está a per

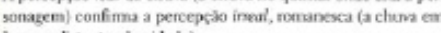
hugares distantes da eidade]

\section{5 de dearntion}

"Alice esperou que as olhos do $\mathrm{Gata}$ se detinewsen e entio saodou-0, inclinando a cabesa"

Lewis Carroll, Aliee no Puá das Mararilhes.

6 de desembin

Nio se deve repor que o artificio de Julia Macquesim Enene, conaferindo una especie de visio espirihual a pessonagem-nar ndon, apresentose cormo simples trarsferéncia de un pronone

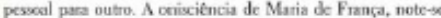

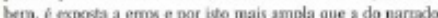

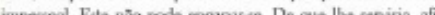

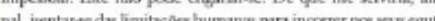

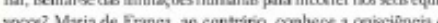
noccos Maria de frope ao mesmo beripo aprisionsse a am "eu" que as restrị̄os humanus enbaraçan. Ocoerem, assim, mais de unra vez, engera

17. Haveria, nesta chacio, cubes pontis a comentar, conno a forms human.

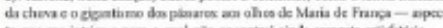

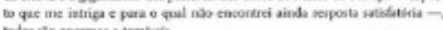

Figura 8. Páginas 82 e 83 do romance. 
Avalovara e A rainha dos cárceres da Grécia, ao refletirem a relação da terra com o escritor, atentam também para uma revisão crítica da história literária brasileira. Nesses livros, destaque-se que o experimentalismo, acoplado à tradição, realiza-se mediante a escolha de elementos diferenciados e tidos até então como antagônicos na expressão da realidade: o aproveitamento do popular e a elaboração artística. Em seus romances, Osman Lins evidenciará que tais esferas não se contrapõem. Ao contrário, na circulação das esferas do popular e do erudito patenteia-se um intercâmbio real que deve ser refletido pela ficção.

Pode-se relacionar a citada perspectiva ao enfoque estabelecido para o diálogo da obra literária com o público. Analisando um e outro, constatase que a preocupação maior do autor se liga à ampliação do espaço que a literatura ocupa na sociedade. Ampliação que implica o aproveitamento de todos os recursos que podem concorrer para este objetivo e o reconhecimento do valor das obras e dos escritores que contribuem para a divulgação do literário no contexto social.

O procedimento reitera-se mediante os disfarces poéticos que compõem o tecido narrativo, como veículos que deixam entrever a posição do escritor diante da obra literária. Reconheço sensíveis conexões entre a obra do romancista e aspectos relevantes da pós-modernidade, como o deslizamento das instâncias produtoras de sentido, a questão do relacionamento entre identidade e alteridade, dos gêneros literários e outras. Parece-me, no entanto, que Osman Lins pretende construir um texto em constante mutação, que se furta, portanto, a rótulos classificatórios.

Percebe-se que o escritor vai partir do imaginário popular para a criação de sua obra. Traz para a cena literária a discussão do papel histórico do oprimido e das formas arbitrárias de exercício das várias facetas do poder. A ficção, portanto, quer-se interpretante crítica do contexto, na tentativa de mobilizar o leitor e afirmar-se enquanto objeto estético. Nesse sentido, dá continuidade a uma ideia sobre a literatura sempre presente na produção do autor e que recai sobre a realidade extraficcional. Não há realidade fora da linguagem nem vida fora do testemunho. Vive-se em função do escrever que, com toda a sua precariedade, se torna o único modo pelo qual se pode conferir sentido àquilo que se experimenta. O ato de escrever, por sua vez, não se dá como pura espontaneidade, em relação com o que seria a matéria bruta do mundo. O escritor pode conferir sentido à experiência apenas na medida em que a situa numa rede de imagens e de significações previamente delimitadas, para serem 
combinadas, relativizadas, no tecido narrativo. A experiência pessoal, inscrita no texto, combina-se com a experiência textual, escrita no contexto literário, fazendo com que o narrar se volte sobre si mesmo, especulando sobre a sua possível razão de ser, seus limites e sua incontrolabilidade, até atingir a interrogação do eu autoral. Este reflete a inquietação da não identidade, porque percebe a multiplicação de seus vários componentes. Volta-se, então, para a recepção, a fim de melhor alcançar a problemática do real romanesco e de suas técnicas, que se vão revelando, conformando, graças ao trabalho textual.

\section{Osman Lins's work: tradition and experimentation}

Abstract: This overview of the work by the writer Osman Lins (19241978) aims to shed some light on certain procedures which he deploys in innovating tradition.

Keywords: Osman Lins, Twentieth-century novel, Tradition and experimentation.

$$
\text { Referências }
$$

ARRIGUCCI Jr., Davi. Achados e perdidos. São Paulo: Polis, 1979.

CANDIDO, Antonio. A nova narrativa. A educação pela noite \& outros ensaios. São Paulo: Ática, 1988.

COSTA LIMA, Luiz. Da existência precária: o sistema intelectual do Brasil. Dispersa demanda: ensaios sobre literatura e teoria. Rio de Janeiro: Francisco Alves, 1981.

FELL, Claude. Un tableaux de la culture brèsilienne. Le Monde, Paris, 31 de oct., 1980.

GATEAUX, Jean-Charles. Trois romans parlent de leur pays et du monde par des voix des femmes. Journal de Génevè. Génève, 7 juin, 1980. Samedi Litteraire III.

LINS, Osman. O fiel e a pedra. São Paulo: Summus,1961.

LINS, Osman. Guerra do 'cansa-cavalo'. Petrópolis: Vozes, 1967.

LINS, Osman. Nove, novena. São Paulo: Melhoramentos, 1966.

LINS, Osman. Avalovara. São Paulo: Melhoramentos, 1973.

LINS, Osman. Guerra sem testemunhas: o escritor, sua condição e a realidade social. 2.ed. São Paulo: Ática, 1974.

LINS, Osman. Lima Barreto e o espaço romanesco. São Paulo: Ática, 1976.

LINS, Osman e outros. Missa do galo, variações sobre o mesmo tema. São Paulo: Summus, 1976. 
LINS, Osman. A rainha dos cárceres da Grécia. São Paulo: Melhoramentos, 1976.

LINS, Osman. Do ideal e da glória, problemas inculturais brasileiros. São Paulo: Summus, 1977.

LINS, Osman. Evangelho na taba, outros problemas inculturais brasileiros. São Paulo: Summus, 1979 .

LINS, Osman. Entrevista a José Mário Rodrigues, Jornal do Comércio, Recife, 28 nov. 1976.

LINS, Osman. Entrevista a Carmem Cagno, Veja, São Paulo, 19 jul. 1978.

SANTIAGO, Silviano. Vale quanto pesa. Rio de Janeiro: Paz e Terra, 1982. 